\title{
Tailored Surgical Approaches for Foramem Magnum Tumors
}

\section{Abordagens personalizadas aos tumores do forame magno}

\author{
Jose Carlos Lynch ${ }^{1}$ Celestino Esteves Pereira ${ }^{2} \quad$ Leonardo C. Weling $^{3}$ Mariangela Gonçalves ${ }^{4}$
}

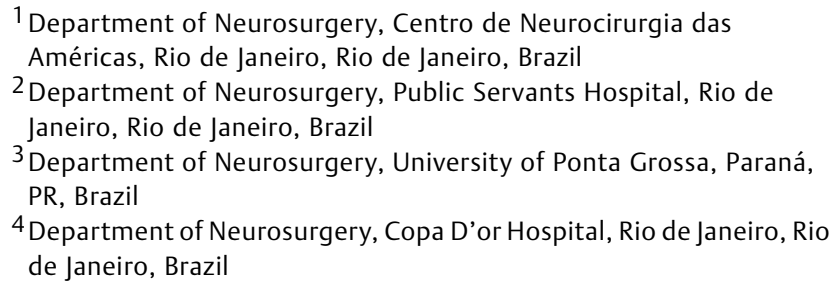

Address for correspondence Jose Carlos Lynch, MD, Centro de Neurocirurgia das Americas, Rio de Janeiro, Rio de Janeiro, Brazil (e-mail: jclynch@globo.com).

Arq Bras Neurocir 2020;39(2):61-67.

\begin{abstract}
Keywords

- foramen magnum

- foramen magnum meningiomas

- foramen magnum tumors

- microsurgery

- retrocondylar approach

- suboccipital approach

\section{Resumo}

Palavras-chave

- foramem magnum

- meningiomas do foramem magnum

- tumores do foramem magnum

- microcirurgia

- acesso retrocondilar

- acesso suboccipital

Objective To describe our surgical techniques, analyze their safety and their postoperative outcomes for foramen magnum tumors (FMTs).

Methods From 1986 to 2014, 34 patients with FMTs underwent surgeries using either the lateral suboccipital approach, standard midline suboccipital craniotomy, or the far lateral approach, depending on the anatomic location of the lesions.

Results In the present series, there were 22 (64.7\%) female and 12 (35.2\%) male patients. The age of the patients ranged from 12 to 63 years old. We observed 1 operative mortality (2.9\%). A total of 28 patients (82.3\%) achieved a score of 4 or 5 in the Glasgow Outcome Scale (GOS). Gross total resection (GTR) was obtained in 22 (64.7\%) patients. After the surgery, 9 (26\%) patients developed lower cranial nerve dysfunction (LCNd) weakness. The follow-up varied from 1 to 24 years (mean: 13.2 years).

Conclusion The majority of tumors located in the FM can be safely and efficiently removed using either the lateral sub occipital approach, standard middle line sub occipital craniotomy, or the far lateral approach, depending on the anatomic location of the lesions.

Objetivo Descrever as nossas técnicas cirúrgicas, analisar sua segurança, relatar e discutir os resultados para tumores localizados no foramen magnum (FM).

Método Este um estudo retrospectivo de 34 pacientes com tumores localizados no FM que foram submetidos a craniectomia suboccipital lateral, ou a craniectomia clássica suboccipital, ou ainda ao acesso extremo lateral, entre os anos de 1986 a 2014. Resultados Este grupo de pacientes foi composto por 12 homens (35.2\%) e 22 (64.7\%) mulheres, cuja idade variou de 12 a 63 anos. A remoção total da lesão ocorreu em $22(64,7 \%)$ indivíduos. A mortalidade cirúrgica foi observada em apenas 1 paciente (2,9\%). Um total de 28 (82.3\%) pacientes alcançaram 4 ou 5 pontos na Escala de Resultados de Glasgow. O acompanhamento médio foi de 13,2 anos.
\end{abstract}

received

October 23, 2018

accepted

June 12, 2019
DOI https://doi.org/

10.1055/s-0039-1695015. ISSN 0103-5355.
Copyright $(2020$ by Thieme Revinter

Publicações Ltda, Rio de Janeiro, Brazil
License terms

(요 (1) $\Theta \circledast$ 
Conclusão A maioria dos tumores localizados no FM podem ser removidos adequadamente empregando-se ou a craniectomia suboccipital lateral retrocondilar, o acesso mediano clássico ou, em raros casos, o acesso extremo lateral.

\section{Introduction}

The foramen magnum (FM) comprises a bony channel formed anteriorly by the lower third of the clivus, the anterior arch of the atlas, and the odontoid process. The lateral limits are the jugular tubercle (JT), the occipital condyle (OC), and the lateral mass of the atlas. Lastly, the FM is limited posteriorly by the lower part of the occipital bone, the posterior arch of the atlas, and the two first intervertebral spaces. The FM encloses the brainstem, the vertebral arteries (VAs), the anterior and posterior spinal arteries, the IX, X, XI, XII cranial nerves and the roots of the C2. Despite the great development of microsurgery, the surgical management of tumors located in the FM continues to challenge neurosurgeons because of the complex anatomy of this region. These tumors grow in close contact with neural and vascular structures that cannot be sacrificed or retracted. It raises controversies related to the best surgical approaches to deal with these lesions. ${ }^{1-13}$

\section{Method}

\section{Data Collection}

A retrospective study was performed with 34 consecutive patients with foramen magnum tumors (FMTs) diagnosed and operated at the Department of Neurosurgery of the Public Servants Hospital, a tertiary referral center, and at Rede D’Or/São Luis hospital, a private unit at Rio de Janeiro, from 1986 to 2014. The files, operative notes, pre and postoperative imaging studies, pathological reports and, when available, intraoperative videos of the patients, were used for the analysis. A database was created, from which information pertinent to the present study was collected. The pathological review was performed based on the World Health Organization (WHO) guidelines. Postoperative imaging was performed within the first 72 hours after the surgery to document postoperative changes and the degree of tumor removal. Neurophysiological monitoring was used in the last 2 cases. The need for informed consent was waived due to the retrospective character of the study. The follow-up varied from 1 to 24 years. The first clinic visit was $\sim 15$ days after hospital discharge, and then at 2 and 6 months postoperatively; thereafter, the patients were reexamined as necessary. The Glasgow Outcome Scale (GOS) defined the outcome.

\section{Clinical Characteristics}

Chronic headache and/or neck and arm pain were the symptoms observed in 19 individuals (55,8\%). Gait disturbance was reported in 21 patients (61.7\%). Pyramidal syndrome was observed in 19 patients (55.8\%). Lower cranial nerve dysfunction (LCNd) was diagnosed in 11 individuals (32.3\%). All of the patients underwent a computed tomogra- phy (CT) scan and/or a magnetic resonance imaging (MRI) exam. A total of $20(58.8 \%)$ lesions showed enhancement after contrast injection. Two (5.8\%) of them showed calcifications. Twenty (58.8\%) of the tumors were inserted anteriorly or anterolaterally to the dentate ligament; 14 lesions (41.1\%) were posterior or posterolateral. Twelve lesions (35.2\%) crossed the midline. ( - Table $\mathbf{1}$ )

\section{Surgical Technique}

The same surgical technique was used following these general steps: anesthesia was induced with a carefully endotracheal intubation and standard anesthetic equipment was employed to detect and treat air embolism. A total of 21 (61.7\%) patients were positioned on a semisitting position with the head slightly flexed and secured in the Mayfield

Table 1 Demographic features, histopathological types, and results of 34 patients with foramen magnum lesions

\begin{tabular}{|l|}
\hline Age of treatment: 12 to 66 years old (mean: 42.6 years old) \\
\hline Gender: female $=22$ ( $64.7 \%)$ male $=12$ (35.2\%) \\
\hline Symptoms: \\
\hline Headache: 20 (58.8\%) \\
\hline Gait disturbance: 22 (64.7\%) \\
\hline Motor deficits: 20 (58.8\%) \\
\hline Lower cranial nerve dysfunction: 12 (35.2) \\
\hline Pathological entities: \\
\hline Meningiomas:16 (47.0\%) \\
\hline Brainstem astrocytomas: 8 (23.5\%) \\
\hline Schwannomas: 4 (11.7\%) \\
\hline Epidermoids: 2 (5.8\%) \\
\hline Chordoma: 1 (2.9) \\
\hline Chondrosarcoma: $1(2.9 \%)$ \\
\hline Ependymoma: 1 (2.9\%) \\
\hline Arachnoid cyst: $1(2.9 \%)$ \\
\hline Tumor size: 2.1 to 7.3 cm (mean: 3.6 cm). \\
\hline Gross total resection in non-meningiomas: 12 (66.6\%) \\
\hline Gross total resection meningiomas: 12 (75.0\%) \\
\hline Cerebrospinal fluid fistula: 7 (20.5\%) \\
\hline Lower cranial nerve deficits: 10 (29.4\%) \\
\hline Recurrence: 9 (26.4\%) \\
\hline Operative mortality: 1 (2.9\%) \\
\hline Follow-up: 1 to 24 years (mean: 10.2 years). \\
\hline Glasgow outcome scale 4 and 5: 25 (73.5\%) \\
\hline
\end{tabular}


head holder. In the other (38\%) patients, the lateral decubitus or the park bench position was chosen. The procedure was initiated with the use of a 2.5 surgical loupe and coaxial lighting for soft tissue incision and bone work.

Skin incision and muscle dissection: For tumors located anterior to the dentate ligament, a $12-\mathrm{cm}$ vertical linear incision was made 2 to $3 \mathrm{~cm}$ medially to the mastoid and centered $\sim 2 \mathrm{~cm}$ above the mastoid tip. The incision was carried down through the galea and the periosteum over the suboccipital bone and the posterior border of the sternocleidomastoid and trapezius muscles, proceeding to the C2-C3level.

Muscular Dissection: The spinous process of the second cervical vertebra is a palpatory guide to the position of the FM and enables the subperiosteal dissection of the suboccipital region to be carried along the $\mathrm{C} 1$ posterior arch. The paravertebral muscles are detached from their attachment to the occipital scama and are progressively sectioned with a scalpel. A self retained retractor is progressively inserted into the wound, exposing the suboccipital triangle and maintaining the paravertebral muscle in the appropriate position. At this point, the C1cposterior arch is identified and dissected free with a periosteum elevator until the mastoid process is exposed. The vertebral artery (VA) is kept undisturbed in the sulcus arteriosus. The ipsilateral lateral half of the arch of the atlas is then resected with the Laksell rongeur, as previously described $^{14}$

Craniotomy: The suboccipital craniotomy is performed unilaterally; it is extended to the FM and to the posterior edge of the occipital condyle, but the condyle is preserved in most of the cases. This access provides sufficient midline and lateral suboccipital exposure to the tumor. If more exposure is needed, C2 and C3 laminectomy can be included. Emissary veins opened during subperiosteally dissection should be coagulated bipolarly and waxed immediately.

Opening the dura: The surgical microscope is introduced in the operative field and the operation is performed with a magnification that varies from $10 x$ to $16 x$ until the end of the procedure. The dura is opened longitudinally, medial from the VA entry or in the midline in the cases of a standard suboccipital approach. The dural edges are tented up. The arachnoid space of the cisterna magna is opened to drain the cerebrospinal fluid (CSF). The tumor is exposed under the arachnoid space of the lateral medullary cistern, enabling visualization of the brainstem, of the LCN and of the VA. The exposure can be improved after a gentle elevation of the cerebellum. The spinal cord and the midbrain are displaced posteriorly and laterally, to the opposite side of the tumor. The spinal portion of the accessory, the XI CN and the posterior rootlets of $\mathrm{C} 2$ are identified on the posterior-lateral aspect of the meningioma. The dentate ligament and $\mathrm{C} 2$ rootlets are sectioned whenever necessary, but the vessel traveling along the nerve root should be preserved to avoid spinal cord ischemia.

Debulking the tumor: After bipolar coagulation with low current under saline irrigation, the tumor is partially devascularized; the capsule is incised with a scalpel, penetrated, and progressively debulked from within, with piecemeal tissue removal techniques. Rigorous homeostasis is maintained throughout the operation. Careful attention is paid to identify and respect the arachnoid plane at the tumorbrainstem interface, which facilitates complete tumor resection and minimizes small vessel and brainstem injury, as previously published.$^{14,15}$

Dissecting the tumor: The surgery proceeds within the space provided by the tumor growth. The meningioma is then dissected away from the LCNs and from the blood vessels by gentle meticulous microsurgical techniques, with microscissors and dissectors and multiple microscope angulations. As the debulking of the tumor proceeds, the brainstem relaxes progressively and provides additional working space for dissection around the capsule.

Then, the site of attachment of the tumor is identified, coagulated, and sectioned. A GTR is always attempted, but if the arachnoidal cleavage plane cannot be defined during surgery, or if dissection of the tumor from the VA, from its branches, from the brainstem or from the LCN may entail risk of damage, we leave a thin rim of tumor attached to these structures. In case of meningiomas, no attempts are made to resect the dura or to excise the bone involved.

In the cases of posterior or posterolateral lesions, as in brainstem gliomas, the skin incision is placed in the midline and the access to the suboccipital scama is made between the paravertebral muscles. The microsurgical removal of the lesions is made following the aforementioned technical rules.

The dura is closed either primarily or with a free pericranial graft. The closure of superficial planes consists of three layers of suture, with nylon stitches on the skin. If swallow deficits are noted in the postoperative period, an early tracheotomy is performed. ${ }^{15}$

\section{Results}

In the present series, there were 22 (64.7\%) female and 12 (35.2\%) male patients, whose age ranged from 12 to 66 years old (mean: 42.6 years old). The follow-up varied from 1 to 24 years (mean: 10.2 years old). The pathological entities comprised: 16 meningiomas, 8 brainstem gliomas, 4 schwannomas, 2 epidermoid tumors, 1 chordoma, 1 chondrosarcoma, 1 ependymoma, and 1 arachnoid cyst. The diameter of the tumors ranged from 2.1 to $7.3 \mathrm{~cm}$ (mean: $3.6 \mathrm{~cm}$ ).

\section{Mortality, Morbidity and Outcome}

There was 1 (2.9\%) operative mortality (until 30 days postsurgery) that occurred in an adolescent with Neurofibromatosis type 1 (NF1). We completely removed 2 dumbbell C2 Schwannomas involving both sensory and motor rootlets with critical compression of the spinal-medullary junction. Several days after surgery, he was admitted with acute respiratory distress and died due to aspiration pneumonia. Three other patients $(8.8 \%)$ died between the $60^{\text {th }}$ and $180^{\text {th }}$ postsurgical days resulting from aspiration pneumonia and its consequences. Immediate postoperative dysfunction or aggravation of previous lower cranial deficits was observed in the 10 patients with aggravation of previous lower cranial deficits, only 3 recovered in the follow-up. Three of these patients recovered partially from the LCN deficits during the follow-up period. One patient presented partial brachial plexus paralysis and in 7 (20.5\%) 
transient CSF fistula. Difficulty with dissection of the tumor from the brainstem and from encased vessels due to absent arachnoid plane occurred in 14 instances (41.1\%). In the meningioma subset, we obtained Simpson grade 2 in 12 individuals (75\%) and grade 3 or 4 in $4(25 \%)$ patients. No operative mortality was observed in the meningioma group. In general, 25 patients (73.5\%) achieved GOS 4 or 5 . Out of 19 patients with non meningioma tumors, we obtained GTR in 11 (57.8\%) individuals. We observed recurrence of the lesion in 9 patients (26.4\%), who were treated with radiotherapy.

\section{Discussion}

\section{Surgical Aspects}

Based on the insertion in the dura, the FM meningiomas (FMMs) can be classified as anterior, if they were attached to the anterior rim of the FM and displaced the neuraxis in a posterior direction ( - Fig. 1). Anterolateral meningiomas are those situated on the ventrolateral rim of the FM and that displace the neuraxis posterolaterally ( - Fig. 2 A and 2B). Tumors in both subgroups were located ventral to the dentate ligament. Lesions are classified as posterior if the insertion in the dura is posterior to the dentate ligament (-Fig. 3). Most of the FMMs arise anterolaterally, followed by those that arise posterolaterally $2,13,14$.

Surgery of FMTs, located anteriorly or anterolaterally to the brainstem constitutes a formidable challenge to neurosurgeons. A controversial discussion has risen concerning the utility of systematic occipital condyle drilling for approaching anterolateral FMMs. Sen et $\mathrm{al}^{8}$ and a group of surgeons stated that, in anteriorly or anterolaterally located FMMs, the extreme lateral or far lateral approach associated with VA medial transposition with a total or partial condylectomy improves the angle of visualization of the area ventral to the lower brainstem, facilitating the dissection of the interface between the neuroaxis and the tumor. ${ }^{4,7,8,16-18}$ On the other hand, George et $\mathrm{al}^{12}$ Bassiouni et $\mathrm{al}^{13}$ and others ${ }^{19-21}$ concluded that, as the tumors progressively displace the medulla and the spinal cord posteriorly, they create a space and, trough this space, the tumor can be safely and completely resected via posterolateral suboccipital craniotomy, without condylar drilling. Most of the cases of incomplete tumor resections are not the result of inadequate exposure, but instead of invasion of the pia mater of the brainstem or of the involvement of the VA or of the cranial nerves by the tumor. In these patients, a subtotal tumor resection is recommended, which leaves a thin rim of the tumor. ${ }^{4-7,19-21}$ Wanebo et $\mathrm{al}^{22}$ concluded that, in patients with a small foramen magnum, with a short distance between the anterior rim of the foramen magnum and the brainstem and relatively large occipital condyles, the transcondylar approaches would be helpful. On the contrary, Spektor et $\mathrm{al}^{23}$ reported that total resection of the condyle provided very little additional exposure to the anterior FM and did not compensate for the significant level of possible additional morbidity. Silveira et $\mathrm{al}^{24}$ concluded that the extensions of bone removal should be adapted to the topography of the lesion: the retrocondylar approach for the lateral area of the FM; the partial transcondylar for the anterolateral portion; and the complete transcondylar for the anterior part of the FM. ${ }^{25,26}$ A recent review found 657 cases from 29 different neurosurgical centers reveled that in 6 they routinely performed condylar resection, in 4 they tailored the drilling of the condyle and 7 others centers they never resect it. ${ }^{1}$

We order the lateral sub-occipital retrocondylar approach without resection of the occipital condyle for 16 patients (47.0\%), (-Fig. 1 and 2 ) the standard posterior midline access for $14(41.1 \%$ ) individuals (-Fig. 1, 4 and -Fig. 5). For one patient with a chondrosarcoma, another with a chordoma, and for two others with huge bilateral epidermoid tumors

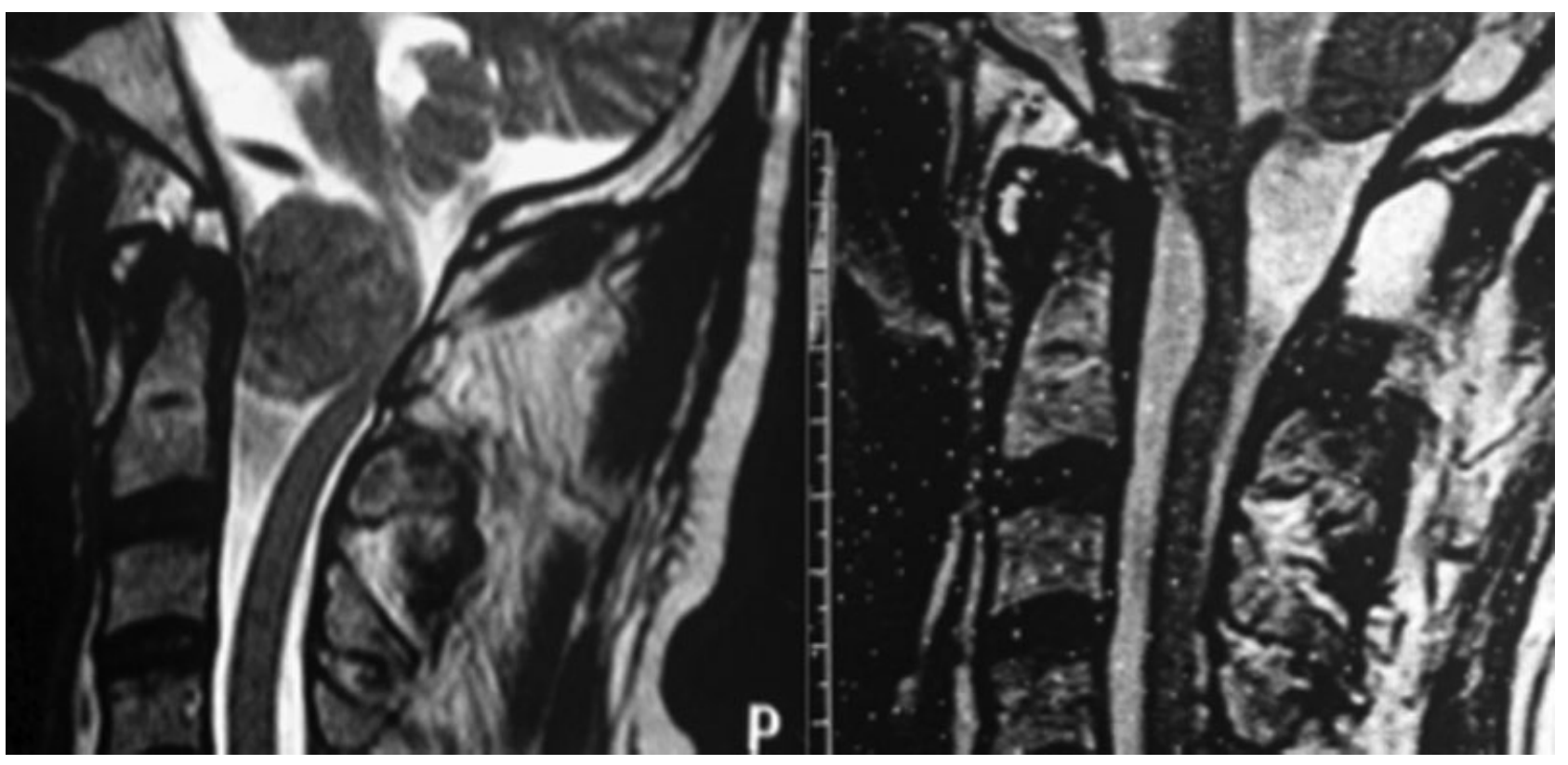

Fig. 1 (A) Preoperative sagittal magnetic resonance imaging detecting a large foramen magnum meningioma displacing the brainstem backwards. (B) Postoperative sagittal magnetic resonance imaging confirming gross total resection after a retrocondylar approach. 

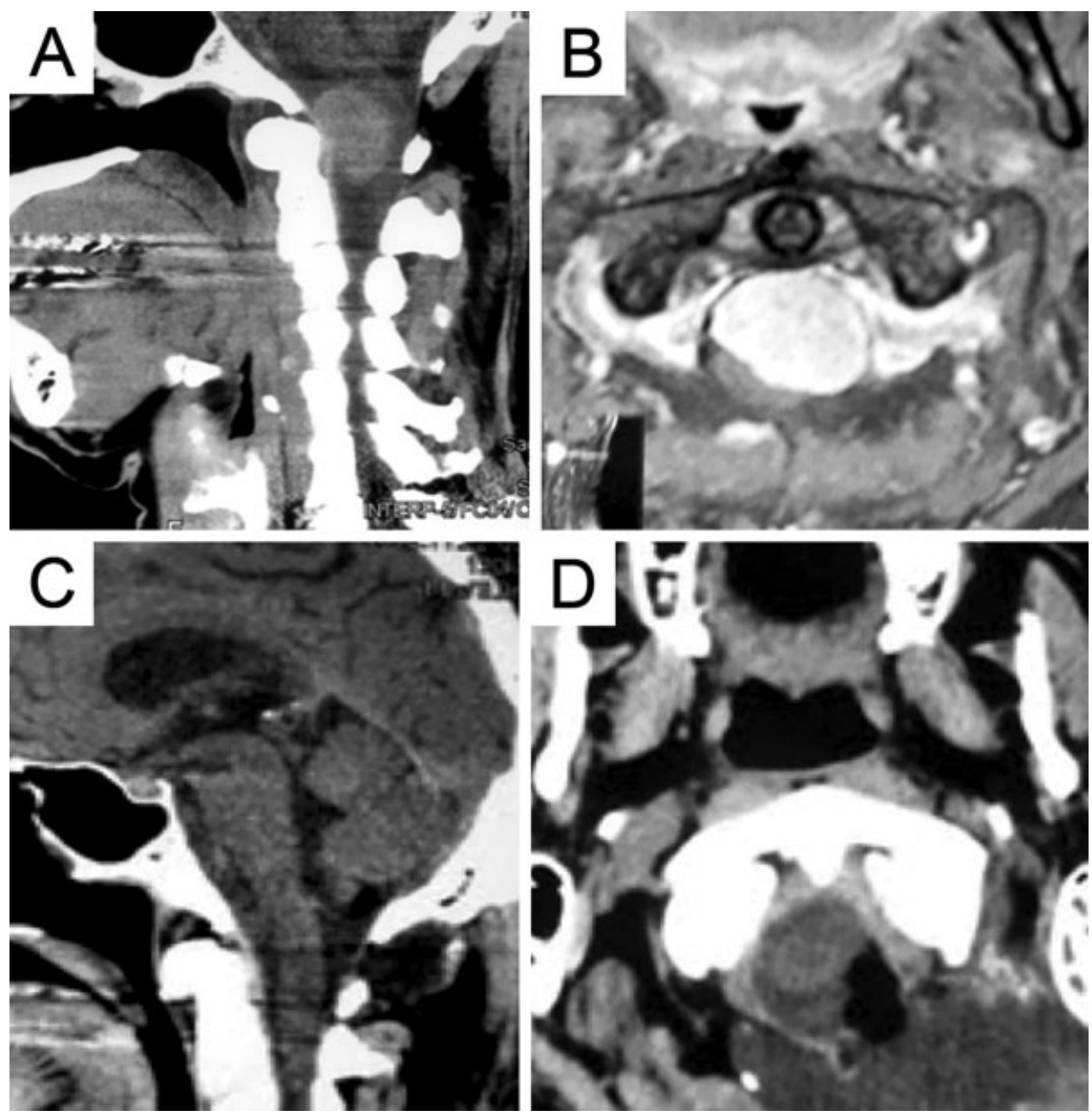

Fig. 2 ( $A$ and B) Computed tomography scans detecting an anterolateral meningioma pushing back the brainstem. (C and D) Postoperative computed tomography scans demonstrating gross total resection with condylar preservation.
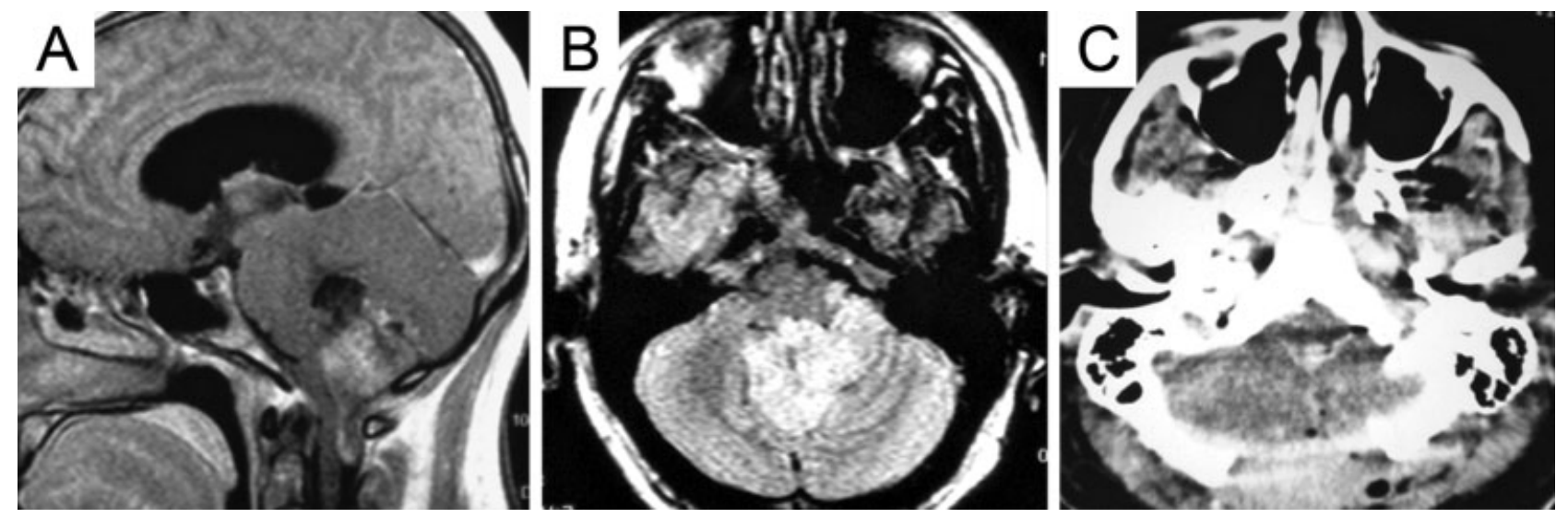

Fig. 3 (A and B) Sagittal T1 and axial contrast-enhanced magnetic resonance imaging detecting a posterior foramen magnum meningioma. (C) Postoperative enhanced computed tomography showing gross total resection, obtained by the standard posterior approach.

with encasement of the basilar artery, we elected the far lateral approach with partial or total condylar resection (11.7\%). The retrocondylar approach provided satisfactory exposure in the majority of the patients, because most of these anterior or anterolateral tumors grow predominantly to one side, providing a corridor of exposure without need of condylar resection. These lesions belong to the group of tumors in which, paradoxically, it is easier to excise a large tumor than a small one, because the larger tumors provide more space anteriorly and, thus, lessen the need for a more lateral exposure. Extensive drilling of the occipital condyle, of the lateral mass of the atlas and of the jugular tubercle can lead injury to the hypoglossal nerve, to the VA, and promote spinal instability. $3,6,7,13,14,20,21,24-26$ Since our objective has 

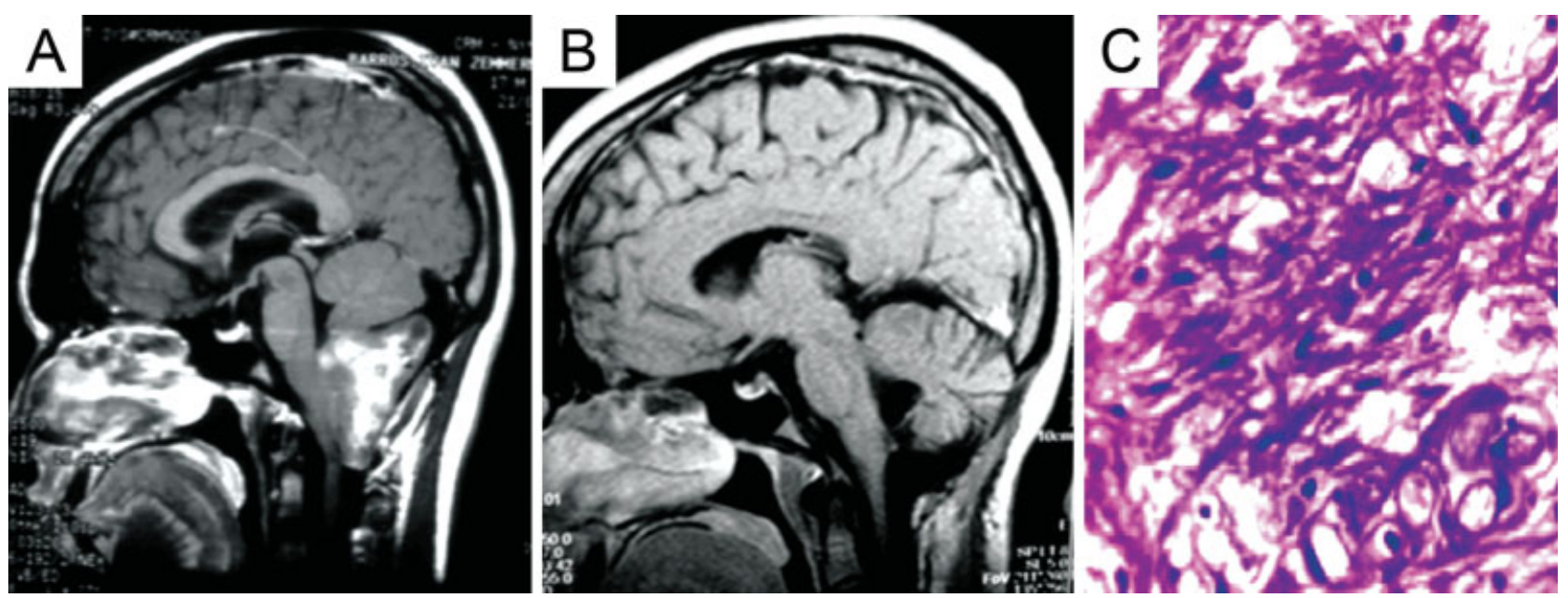

Fig. 4 (A) Preoperative contrast-enhanced sagittal T1-weighted magnetic resonance imaging showing a large lesion occupying the $4^{\text {th }}$ ventricle with anterior compression of the brainstem . (B) Postoperative sagittal T1-weighted magnetic resonance imaging confirming the gross total resection of the tumor. (C) Histopathological study revealed elongated fibrillated pilocytic astrocytes (hematoxylin and eosin, 20x).
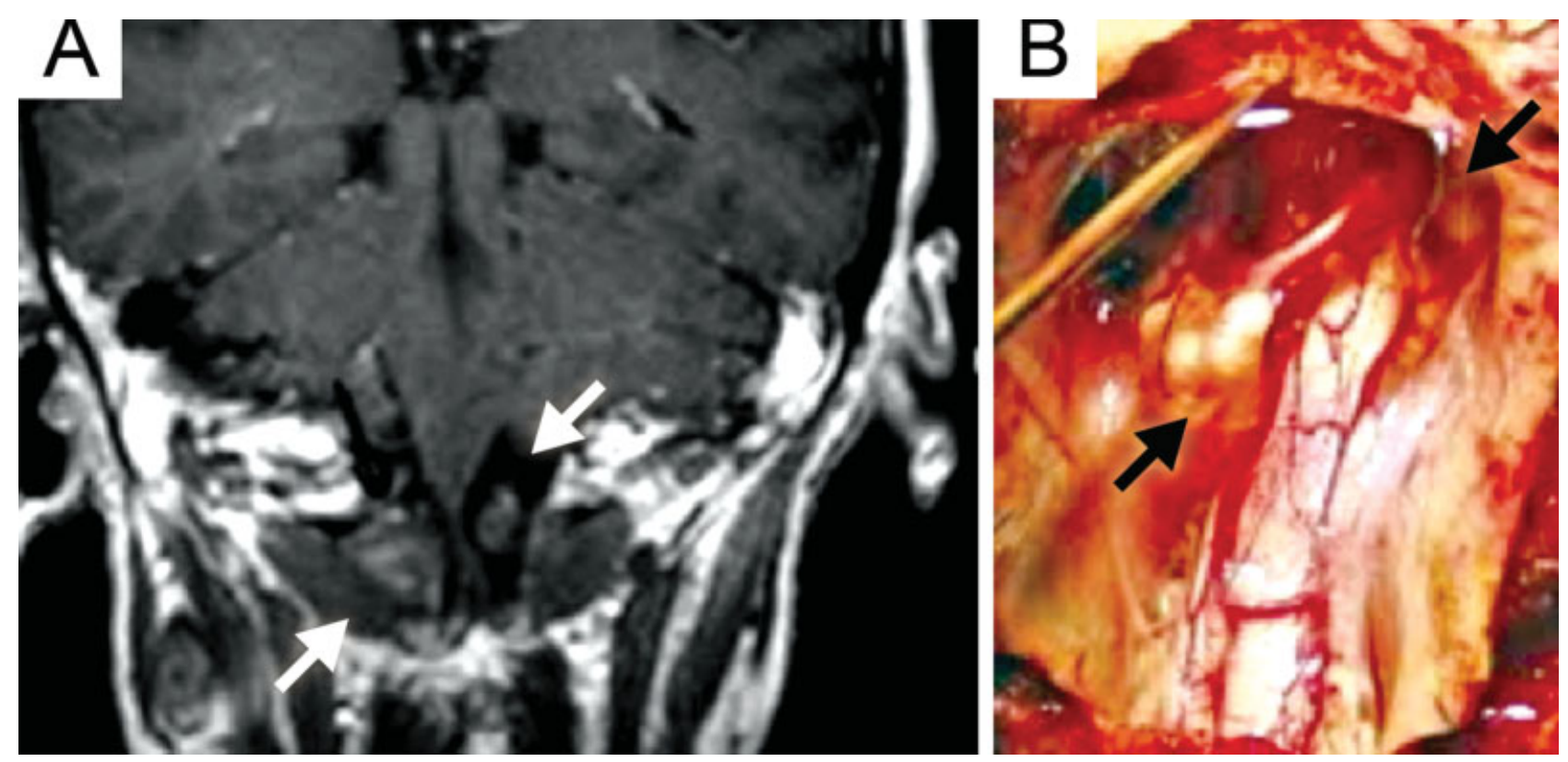

Fig. 5 (A) Coronal T1 magnetic resonance imaging detecting fainting enhancing bilateral foramen magnum tumors (arrows). (B) Operative photographs revealing the presence of bilateral foramen magnum schwannomas (arrows).

always been to keep the quality of life of the patients a priority, a subtotal removal might represent a very acceptable goal in fibrous or calcified tumors encasing the VA and perforating vessels or adhering to cranial nerves. ${ }^{4-7}$ In these patients, a subtotal tumor resection is recommended, which leaves a thin rim of the tumor. ${ }^{4-7,19-21}$ Most of the cases of incomplete tumor resections are not the result of inadequate exposure, but instead of invasion of the pia mater of the brainstem or of the involvement of the VA or of cranial nerves by the tumor. During the removal of the tumor, bipolar coagulation is kept to a minimal, used under continuous cold saline irrigation, and the aspiration is seated in soft suction mode. Total removal could be dangerous for some patients and difficult to achieve because these tumors are critically located, and there may be adherence or even encasement of vital structures by the tumor. If the surgeon persists with any attempt to remove every last residual lesion to achieve the cure of the patient, it could result in unwarranted lesions or injuries in the perforating branches. The main cause of postoperative morbidity is injury to the vertebral or basilar artery branches. Injury to even a single perforating vessel can result in brainstem infarction. On diagnosis, many lesions are already large or giant. Several authors reported increasing tumor size to portend higher rates of incomplete resection, higher rates of surgical morbidity, and an increased risk of recurrent disease. The decision on the extent of surgical resection can be difficult, particularly in older patients or in patients with minor symptoms. On the other hand, experience clearly emphasizes that, when tumors are incompletely removed, they tend 
to regrow, and the next surgeon operating on the patient will be confronted with severe adhesions of blood vessels and brain tissue.

However, even when GTR is performed, tumor recurrence can occur. Radiosurgery might be considered as an alternative therapy for residues or recurrences, or even for patients deemed poor candidates for resection. ${ }^{26}$

The role of the endoscopic endonasal approach in the management of ventral posterior fossa meningiomas is still restricted due to limited surgical indications and experience. It can be use for the rare cases of meningiomas with most parts of its dural base at the midline clival region. Most of these patients were operated on by two senior neurosurgeons that gave to this sample a homogenous surgical technique. The limitation of the present study is that, compared with other published series, the present series is relatively small.

We can conclude that, in most of the cases of anterior or anterolateral FMTs, the lateral suboccipital approach without drilling the occipital condyle is less invasive, but it is sufficient for tumor removal. This approach is safe and effective. However, tailoring the surgery, including drilling of the occipital condyle, based on the size and shape of the FM, and on the local of the dural origin of the meningioma, also seems a reasonable option. In posterior or posterolateral located lesions, the standard posterior midline is sufficient.

Conflict of Interests

The authors have no conflict of interests to declare.

\section{References}

1 Cusimano MD, Faress A, Chang Y, Luong W. Foramen Magnum Meningiomas in Al-Meftys Meningiomas. De Monte F, McDermott MW, Al-Mefty O (eds), $2{ }^{\text {nd }}$ ed, ThiemeNY2011:297-309

2 Arnautović KI, Al-Mefty O, Husain M. Ventral foramen magnum meninigiomas. J Neurosurg 2000;92(1, Suppl)71-80

3 Lot G, George B. The extent of drilling in lateral approaches to the cranio-cervical junction area from a series of 125 cases. Acta Neurochir (Wien) 1999;141(02):111-118

4 Yasargil MG, Mortara RW, Curcic M. Meningiomas of basal posterior cranial fossa. Adv Tech Stand Neurosurg 1980;7:3-115

5 Pirotte BJ, Brotchi J, DeWitte O. Management of anterolateral foramen magnum meningiomas: surgical vs conservative decision making. Neurosurgery 2010;67(3, Suppl Operative)ons58-ons70, discussion ons70

6 Bertalanffy H, Gilsbach JM, Mayfrank L, Klein HM, Kawase T, Seeger W. Microsurgical management of ventral and ventrolateral foramen magnum meningiomas. Acta Neurochir Suppl (Wien) 1996;65(Suppl):82-85

7 Sekhar LN, Swamy NK, Jaiswal V, Rubinstein E, Hirsch WE Jr, Wright DC. Surgical excision of meningiomas involving the clivus: preoperative and intraoperative features as predictors of postoperative functional deterioration. J Neurosurg 1994;81(06):860-868

8 Sen CN, Sekhar LN. An extreme lateral approach to intradural lesions of the cervical spine and foramen magnum. Neurosurgery 1990;27(02):197-204
9 de Oliveira E, Rhoton AL Jr, Peace D. Microsurgical anatomy of the region of the foramen magnum. Surg Neurol 1985;24(03):293-352

10 Pamir MN, Ozduman K. Foramen magnum meningiomas. In: Pamir MN, Black PM, Fahlbusch R. Editors. Meningiomas a comprehensive text. WB SaundersChina2010:349-354

11 Margalit NS, Lesser JB, Singer M, Sen C. Lateral approach to anterolateral tumors at the foramen magnum: factors determining surgical procedure. Neurosurgery 2005;56(02, Suppl)324-336, discussion 324-336

12 George B, Lot G, Boissonnet $\mathrm{H}$. Meningioma of the foramen magnum: a series of 40 cases. Surg Neurol 1997;47(04): 371-379

13 Bassiouni H, Ntoukas V, Asgari S, Sandalcioglu EI, Stolke D, Seifert V. Foramen magnum meningiomas: clinical outcome after microsurgical resection via a posterolateral suboccipital retrocondylar approach. Neurosurgery 2006;59(06):1177-1185, discussion 1185-1187

14 Lynch JC, Pereira C, Welling L, Gonçalves M, Zanon N. Extended Retrosigmoid Approach for Angle Meningiomas: Operative Technique and Results. A Series of 28 Patients. J Neurol Surg B Skull Base 2018;79(05):458-465

15 Lynch JC, Welling LC, Aversa A, et al. Surgical Strategy for Dermoid and Epidermoid Tumors of the Posterior Fossa - Experience with 21 Patients. Arq Bras Neurocir 2017;36:145-152

16 Babu RP, Sekhar LN, Wright DC. Extreme lateral transcondylar approach: technical improvements and lessons learned. J Neurosurg 1994;81(01):49-59

17 Borba LAB, Colli BO. Foramen Magno Meningiomas. In: Meningiomas. Diagnosis, Treatment and outcome. Lee JH. editors. London: Springer; 2008:449-456

18 Erkmen K, Bekelis K, Al-Mefty O. Primary Extramedullary tumors of the Cranial Vertebral Junction, in Surgery of the Craniovertebral Junction. Bambakidis NC, Dickman CA, Spetler RF, Sonntag VKH, editors. $2^{\text {nd }}$ ed, New York2013:154-169

19 Samii M, Klekamp J, Carvalho G. Surgical results for meningiomas of the craniocervical junction. Neurosurgery 1996;39(06):1086-1094, discussion 1094-1095

20 George B, Dematons C, Cophignon J. Lateral approach to the anterior portion of the foramen magnum. Application to surgical removal of 14 benign tumors: technical note. Surg Neurol 1988; 29(06):484-490

21 Nanda A, Vincent DA, Vannemreddy PSSV, Baskaya MK, Chanda A. Far-lateral approach to intradural lesions of the foramen magnum without resection of the occipital condyle. J Neurosurg 2002;96 (02):302-309

22 Wanebo JE, Chicoine MR. Quantitative analysis of the transcondylar approach to the foramen magnum. Neurosurgery 2001;49 (04):934-941, discussion 941-943

23 Spektor S, Anderson GJ, McMenomey SO, Horgan MA, Kellogg JX, Delashaw JB Jr. Quantitative description of the far-lateral transcondylar transtubercular approach to the foramen magnum and clivus. J Neurosurg 2000;92(05):824-831

24 Silveira RL, Gusmão S. Variações da extensão anterolateral do acesso suboccipital lateral: estudo anatômico. Arq Neuropsiquiatr 2002;60(2-A):251-257

25 Ma L, Shrestha BK, You C, Hui XH. Revisiting the far lateral approach in the treatment of lesions located at the craniocervical junction-Experiences from West China hospital. Interdiscip Neurosurg 2015;2(03):133-13

26 Bernard F, Lemee JM, Delion M, Fournier HD. Lower third clivus and foramen magnum intradural tumor removal: The plea for a simple posterolateral approach. Neurochirurgie 2016;62(02):86-93 